\title{
The effect of selected ovulation-inducing preparations on post-stripping mortality and reproductive indicators of farmed European grayling (Thymallus thymallus L.)
}

\author{
Jan Turek, Tomáš Randák, Josef Velíšek, Peter Podhorec, Jan Kouřil \\ University of South Bohemia in České Budějovice, Faculty of Fisheries and Protection of Waters, \\ South Bohemian Research Center of Aquaculture and Biodiversity of Hydrocenoses, \\ Research Institute of Fish Culture and Hydrobiology, Vodňany, Czech Republic
}

Received January 25, 2013

Accepted August 28, 2013

\begin{abstract}
An experiment on the effects of hormonal preparations (Gonazon ${ }^{\mathrm{TM}}$ and Supergestran containing gonadotropin-releasing hormone) on the course of reproduction of farmed grayling (Thymallus thymallus L.) broodstock and their post-stripping mortality was performed at the hatchery in spring 2009. Four-year-old marked grayling females $(n=80)$ were randomly divided into four groups. The fish were intramuscularly injected with Supergestran at a dose of $30 \mu \mathrm{g} \cdot \mathrm{kg}^{-1}$ body weight (Group 1), with Gonazon ${ }^{\mathrm{TM}}$ at a dose of $30 \mu \mathrm{g} \cdot \mathrm{kg}^{-1}$ (Group 2) and with saline $0.9 \% \mathrm{NaCl}$ (Group 3), while fish of Group 4 were left without treatment (control group). No effect of treatment on the total number of ovulated females $(70-80 \%)$ was found at the end of the stripping period. Slightly higher (nonsignificant) percentage of ovulated fish in the first stripping time (3 days post injection) was observed in fish treated with Gonazon. The 30-days post-ovulatory mortality remained unaffected by hormone treatments in all groups. Significant differences $(P<0.001)$ were found in the fertilization rate of egg samples from the first stripping time. The highest fertilization rate $(98.6 \%)$ was found in fish treated with Supergestran, lower fertilization rates $(61 \%$ and $65 \%)$ in fish treated with saline and control, respectively, and the lowest fertilization rate (39\%) in fish treated with Gonazon. Other reproductive indicators remained unaffected by treatment in all groups. Based on our results, Supergestran is the most suitable preparation for the enhancing of artificial reproduction efficiency of farmed European grayling in fishery practice. The study brings important information about artificial reproduction of grayling broodstocks reared in controlled conditions.
\end{abstract}

Egg, GnRH, Gonazon, salmonids, Supergestran

European grayling (Thymallus thymallus L.) is a valuable fish species widely distributed in the Northern hemisphere. Their populations have considerably decreased in a majority of the waters in Europe due to many reasons (Uiblein et al. 2001). In the past, capturing wild, mature broodstock at their spawning grounds during the spawning season has led to degradation of mature grayling population in natural rivers and to reduction of natural spawning. Furthermore, the post-spawning mortality of graylings captured in spawning grounds is very high (Luczynski et al. 1986; Harsanyi and A schenbrenner 2002). In order to produce enough fry for restocking purposes and limit the harvesting of wild broodstock, the development of grayling culture methods is one of the best options (Randák et al. 2000).

Artificial reproduction of salmonids faces some problems caused mainly by the changed environment of fish farms which lacks natural spawning stimuli (spawning substrate, stream hydraulics, nutrition, water quality etc.) necessary for successful reproduction. Reproductive dysfunction observed in cultured females of salmonids is the absence of spawning at the end of the reproductive cycle (Mylonas et al. 2010). As a solution, hormonal therapy may be an effective tool to overcome these problems. The discovery of the primary structure of mammalian gonadotropin-releasing hormone GnRH neurodecapeptide (Burgus et al. 1971 ) in early 1970s was important also with regard to possibilities of hormonal therapy of reproductive dysfunctions. The unsatisfactory potency of natural $\mathrm{GnRH}$ peptides was improved by synthesising a superactive GnRHa, which are able to induce a significant increase in luteinizing hormone concentrations and ovulation even at centuple smaller

Address for correspondence:

Jan Turek

Faculty of Fisheries and Protection of Waters

University of South Bohemia in Ceské Budějovice

Zátiší 728/II, 38925 Vodňany, Czech Republic

Phone: +420387774656

E-mail: turek@frov.jcu.cz

http://actavet.vfu.cz/ 
doses than with the use of natural GnRH forms. Therefore, the potency of different GnRH analogues can vary greatly and thus it is very desirable to test the efficiency of different GnRHa in particular fish species in vivo.

The earlier published results with grayling reproduction were focused on wild mature fish. The aim of this study was to evaluate the effectiveness of two commercially available hormonal preparations (Gonazon ${ }^{\mathrm{TM}}$ and Supergestran) containing $\mathrm{GnRH}$ agonists for induction and synchronization of ovulation and post-spawning mortality in farmed (hatchery-reared) European grayling broodstock.

\section{Materials and Methods}

Animals and experimental design

The experiment was carried out at the hatchery of the Czech Anglers Union in Husinec, Czech Republic. Four-year-old cultured grayling females were marked with the passive integrated transpoder tags in autumn 2008 and kept in $50 \mathrm{~m}^{3}$ concrete tanks during the winter. In spring (April 24) 2009, 80 fish were randomly chosen and divided into four groups of 20 fish per group. All fish were weighed and

Table 1. Post hoc Tukey results displaying total length and weight of the tagged grayling females.

\begin{tabular}{lccc}
\hline Group & $\mathrm{n}$ & $\mathrm{L}_{\mathrm{T}}(\mathrm{mm})$ & $\mathrm{W}(\mathrm{g})$ \\
\hline $\mathrm{G}$ & 20 & $267 \pm 16.5^{\mathrm{a}}$ & $191 \pm 25.8^{\mathrm{ab}}$ \\
$\mathrm{S}$ & 20 & $279 \pm 16.7^{\mathrm{b}}$ & $209 \pm 34.8^{\mathrm{b}}$ \\
PS & 20 & $266 \pm 12.0^{\mathrm{a}}$ & $181 \pm 21.8^{\mathrm{a}}$ \\
C & 20 & $281 \pm 15.8^{\mathrm{b}}$ & $206 \pm 33.3^{\mathrm{b}}$ \\
\hline
\end{tabular}

Groups: $\mathrm{G}$ - treated with gonazon, $\mathrm{S}$ - treated with supergestran, PS - treated with physiological saline, $\mathrm{C}$ - control group without treatment. $\mathrm{L}_{\mathrm{T}}$ - total lenght, $\mathrm{W}$ - weight. Data are expressed as mean $\pm \mathrm{SD}$. Within a column, different superscripts letters indicate a significant difference $(P<0.05)$.

$9.5^{\circ} \mathrm{C}$. The course of water temperature during experiment is given in Fig. 1. measured (Table 1). Group 1 of fish was treated with the Supergestran preparation ([D-Tle ${ }^{6}, \quad$ Pro $^{9}, \quad$ NEt $]-m G n R H, \quad$ Nordic Pharma s.r.o, Czech Republic) at a dose of $30 \mu \mathrm{g} \cdot \mathrm{kg}^{-1}$ body weight; Group 2 was treated with the Gonazon ${ }^{\mathrm{TM}}$ preparation (pGlu-His-Trp-Ser-Tyr-[D-Nal(2)]-LeuArg-Pro-[aza-Gly]), Intervet International B.V., Boxmeer, the Netherlands) at a dose of $30 \mu \mathrm{g} \cdot \mathrm{kg}^{-1}$ body weight; Group 3 was treated with saline $(0.9 \% \mathrm{NaCl}$, Braun Melsungen AG, Germany); and Group 4 was left without treatment (control group). All solutions were administered by intramuscular injection. After treatment, fish of each group were placed into a separate $2 \mathrm{~m}^{3}$ flow-through plastic indoor tank with the water temperature around

Females were checked for ovulation every 3-4 days (April 27, 30, May 4 and 7, 2009) after the injection. Ovulated females were stripped manually. All manipulations were done under 2-phenoxyethanol anaesthesia in the bath $\left(0.3 \mathrm{ml} \cdot 1^{-1}\right)$. The weight of stripped eggs was determined for each fish. Egg samples $(\mathrm{n}=20)$ were taken from each stripped fish and the mean egg weight was calculated for each fish. Subsequently, absolute and relative fecundity were determined for each stripped fish.

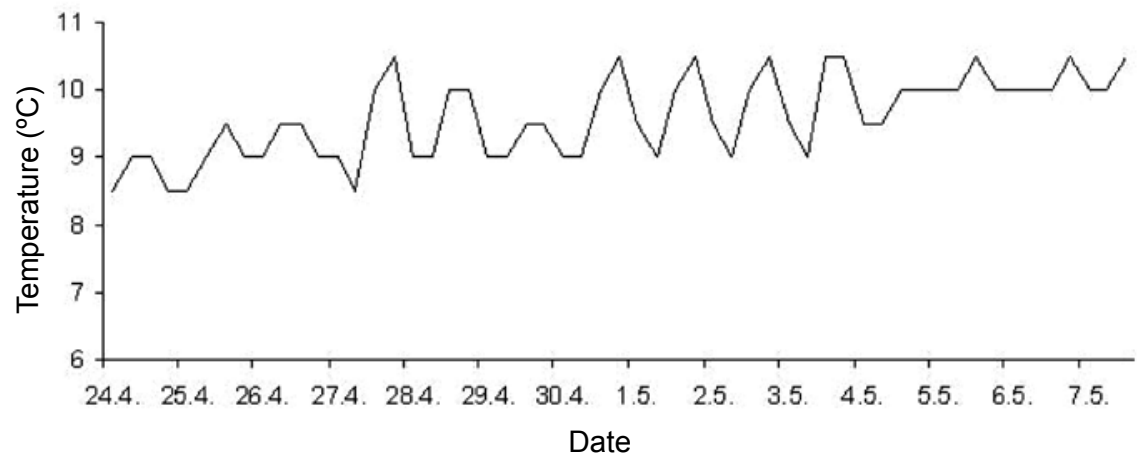

Fig. 1. The course of water temperature during the stripping period (April 24-May 7, 2009). 
Egg viability was evaluated in the first stripping (April 27, 2009). All stripped eggs in each fish group were mixed carefully. In total, 300 eggs from each group were randomly selected. The polysperm from 5 hatcheryreared grayling males was stripped in the syrette (total volume $4 \mathrm{ml}$ ). Each egg sample was fertilized by polysperm $(0.1 \mathrm{ml}$ of polysperm per sample). The fertilized eggs were incubated in divided sections of horizontal hatchery apparature (Rückel-Vacek; producer R. Bednar, r-bednar.cz, 2007). At the eyed stage (May 7, 2009), the egg samples were potted by glacial acetic acid and the number of viable eggs was counted for each group. The last stripping was performed on May 7, 2009.

All stripped females were nursed by a short bath in potash $\left(\mathrm{KMnO}_{4} ; 0.1 \mathrm{~g} \cdot 1^{-1}\right)$ and placed into a small pond $(100$ $\mathrm{m}^{2}$ ). Dead fish were removed every day and identified by tags. During the next 30 days, post-spawning mortality of females was recorded. The experiment was ended on June 6. 2009.

The study was conducted according to the principles of the Ethics Committee for Protection of Animals in Research of the University of South Bohemia, Faculty of Fisheries and protection of Waters, based on the EUharmonized Animal Welfare Act of the Czech Republic (Ref. no. 22761/2009-17210).

\section{Statistical analyses}

One-way ANOVA was used to assess differences among groups of females in case of a weight, length, fecundity and fertility indicators (absolute fertility, relative fertility, weight of stripped eggs from one female, mean weight of one egg). Post hoc comparisons were made by Tukey's Honestly Significant Difference test. Mortality rate, ovulation rate and fertilization rate of egg samples were compared with the Pearson and maximum likelihood $\chi^{2}$ test. Significance was accepted for values of $P<0.05$. D.f. $=$ degree of freedom.

\section{Results}

No significant effect of hormone preparations compared to the control group was determined in case of ovulation at any stripping time (Fig. 2). Slightly more $(60 \%, n=12)$ ovulated females were found in the Gonazon-treated group compared to fish treated with saline $(45 \%, \mathrm{n}=9)$, with Supergestran $(35 \%, \mathrm{n}=7)$ and the control group $(30 \%, \mathrm{n}=6)$ three days post-injection. At the end of experiment, the total number of ovulated females was $70 \%(\mathrm{n}=14)$ in the group treated with Gonazon, $75 \%(\mathrm{n}=15)$ in control and salinetreated fish, and $80 \%(\mathrm{n}=16)$ in the group treated with Supergestran. The mortality rate of non-ovulated females was $15 \%(n=3)$ in the control group, $5 \%(n=1)$ in groups treated with Gonazon and Supergestran during the stripping period (April 24-May 7); in the group treated with saline, no fish died during the stripping period. No significant differences in absolute fertility, relative fertility, mean egg weight and the mean weight of stripped eggs

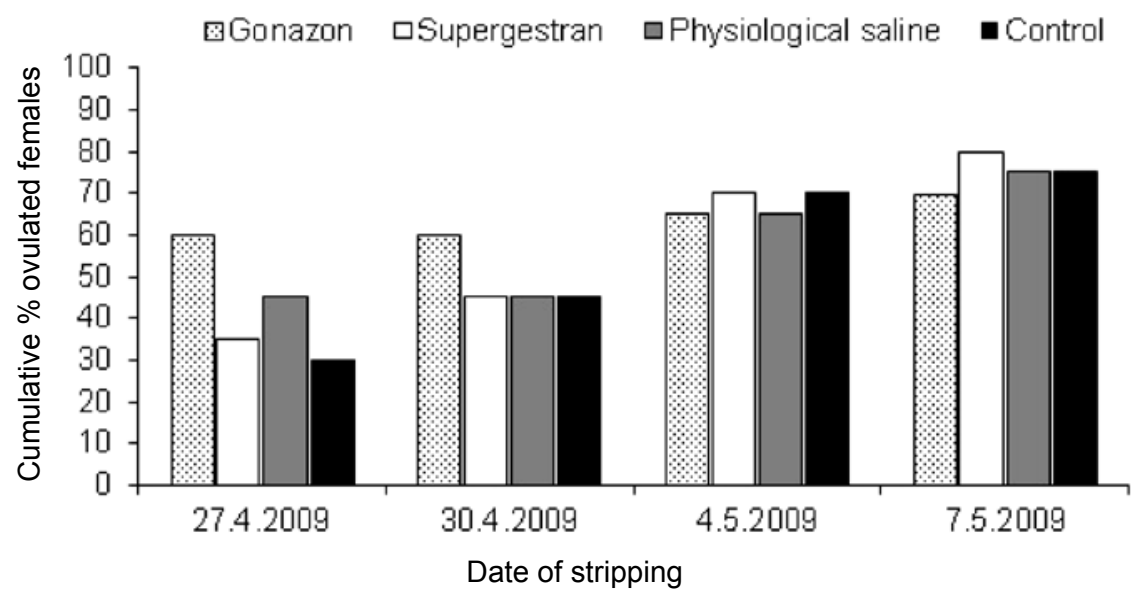

Fig. 2. The course of ovulation of European grayling females treated with Gonazon, Supergestran, saline and without treatment (control). 
Table 2. Post hoc Tukey results displaying absolute fecundity, relative fecundity, weight of stripped eggs and eggs weight of stripped grayling females.

\begin{tabular}{lcccccc}
\hline Group & $\mathrm{n}$ & $\begin{array}{c}\mathrm{AF} \\
(\mathrm{egg} / \mathrm{fish})\end{array}$ & $\begin{array}{c}\mathrm{RF} \\
(\mathrm{eggs} / \mathrm{kg})\end{array}$ & $\begin{array}{c}\mathrm{W} \text { of eggs } \\
(\mathrm{g})\end{array}$ & $\begin{array}{c}\text { Egg W } \\
(\mathrm{mg})\end{array}$ & $\begin{array}{c}\text { Fertilization rate* } \\
(\%)\end{array}$ \\
\hline $\mathrm{G}$ & 14 & $2081 \pm 810^{\mathrm{a}}$ & $11204 \pm 4062^{\mathrm{a}}$ & $28.2 \pm 9.3^{\mathrm{a}}$ & $13.9 \pm 1.4^{\mathrm{a}}$ & $38.8^{\mathrm{a}}$ \\
$\mathrm{S}$ & 16 & $2243 \pm 806^{\mathrm{a}}$ & $10824 \pm 3062^{\mathrm{a}}$ & $28.7 \pm 11.2^{\mathrm{a}}$ & $14.0 \pm 1.6^{\mathrm{a}}$ & $97.6^{\mathrm{c}}$ \\
$\mathrm{PS}$ & 15 & $1949 \pm 824^{\mathrm{a}}$ & $10423 \pm 3612^{\mathrm{a}}$ & $25.2 \pm 9.3^{\mathrm{a}}$ & $14.3 \pm 2.3^{\mathrm{a}}$ & $60.9^{\mathrm{b}}$ \\
$\mathrm{C}$ & 15 & $2172 \pm 1020^{\mathrm{a}}$ & $10153 \pm 4425^{\mathrm{a}}$ & $27.1 \pm 13.2^{\mathrm{a}}$ & $13.5 \pm 2.2^{\mathrm{a}}$ & $65.1^{\mathrm{b}}$ \\
\hline
\end{tabular}

Groups: $\mathrm{G}$ - treated with gonazon, $\mathrm{S}$ - treated with supergestran, PS - treated with physiological saline, C control group without treatment. $\mathrm{AF}$ - absolute fecundity, $\mathrm{RF}$ - relative fecundity, $\mathrm{W}$ of eggs - mean weight of stripped eggs from one female, Egg W - mean weight of one egg. Data are expressed as mean $\pm \mathrm{SD}$. Within a column, different superscripts letters indicate a significant difference $(P<0.05)$. *Fertilization rate of egg samples from the $1^{\text {st }}$ stripping time was evaluated with the $\chi^{2}$ test.

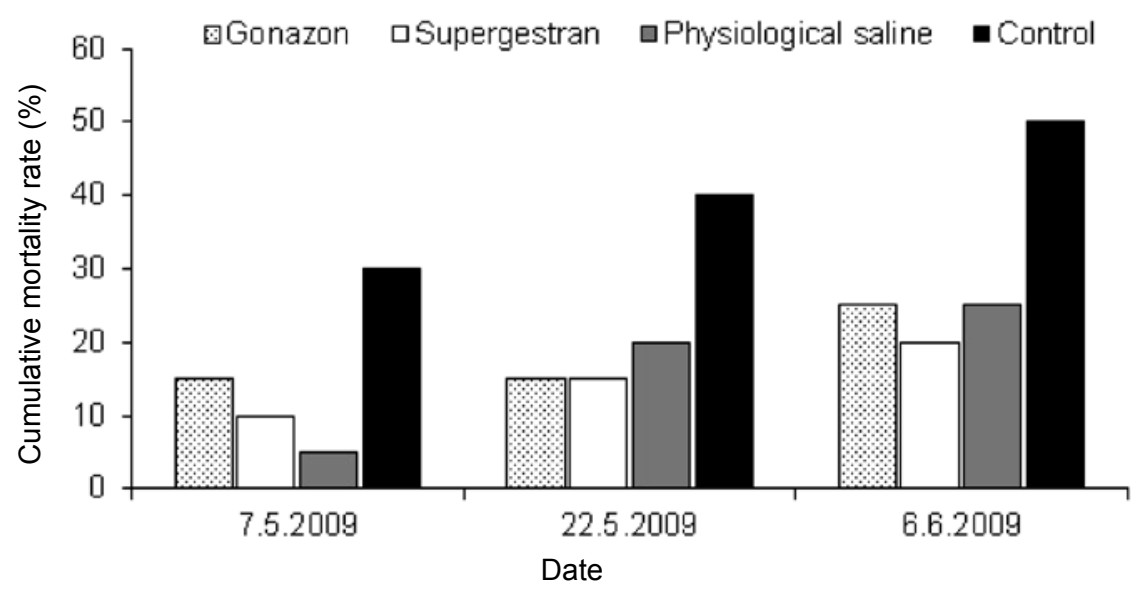

Fig. 3. Thirty days post-stripping mortality of European grayling females treated with Gonazon, Supergestran, saline and without treatment (control).

from 1 female were found between the groups of stripped females (Table 2). At the last ovulation check (May 7), the quality of eggs was the lowest (visual assessment: overripe, softened, with blood) among all ovulated females. Significant differences $\left(\chi^{2}=226.97\right.$; d.f. $=3 ; P<0.001)$ were detected in the fertilization rate of egg samples from the first stripping (Table 2). Post-spawning mortality was unaffected by hormonal administration. The highest 30 days post-stripping mortality of females $(50 \%, \mathrm{n}=10)$ was recorded in the control group, the lowest $(20 \%, n=4)$ in the group treated with Supergestran (Fig. 3).

\section{Discussion}

The present study showed that administration of the hormonal preparations Gonazon and Supergestran did not improve the results of artificial spawning in cultured grayling females. On the contrary, results published by Mikolajczyk et al. (2008) indicated that Gonazon at the dose of $16 \mu \mathrm{g}$ per $\mathrm{kg}$ significantly accelerated and synchronized ovulation in grayling females older than 3 years. A positive effect of synthetic analogues of $\mathrm{GnRH}$ 
hormone and carp pituitary on ovulation in grayling females was published by Kouřil et al. (1987a, b) with no differences between both preparations. Randak et al. (2000) showed no significant effect of (D-Ala ${ }^{6}$ Gn-RH ProNHEt (Kobarelin) on inducing ovulation of wild grayling females. Nevertheless, the authors pointed out that results of their experiment were affected by ideal temperature conditions in contrast to earlier years. In the present study, the course of water temperature without major changes may have contributed to reduction of treatment effects. The age and origin (rearing method) of mature fish are the main differences between the present and most previous studies. Four-year-old fish used in the experiment were sexually mature and part of them had already stripped in the previous season. The rearing of broodstock with feeding by pellets only secured sufficiency of energy for successful maturation. All the above mentioned factors contributed to successful ovulation in all groups of females.

We found differences in the fertilization rate of egg samples from the first stripping. The low fertilization rate of eggs from fish treated with Gonazon could be caused by their overripening between treatment and the first stripping. Higher egg mortality $(4-5 \%)$ in fish treated with Gonazon compared to control was also reported by Mikolajczyk et al. (2008). Some authors observed poor quality of eggs (low fertilization rate and high mortality during the incubation process) from cultured grayling (Pavlík 2000; Leszek et al. 2000). Good quality of eggs from cultured grayling females can be provided by stopping the feeding with industrially produced pellets at the end of September (Harsanyi and Aschenbrenner 2002). The same method of feeding time was used in the present study for broodstock rearing. The fertilization rate observed in fish treated with saline and the control group is consistent with long-term results of grayling reproduction in the Fisheries Educational and Exemplary Centre (Upper Bavaria) reported by Harsanyi and Aschenbrenner (2002). The positive effect of Supergestran treatment on the fertilization rate needs to be verified in specialized experiment.

European grayling is very sensitive to the stress of frequent manipulations, resulting in high mortalities during and after artificial spawning. No observable effect of the treatment on post-stripping mortality in the present study is consistent with earlier results of Mikolajczyk et al. (2008) and Randák (2002). The used anaesthetic concentration of $0.30 \mathrm{ml} \cdot 1^{-1}$ 2-phenoxyethanol is considered safe for rainbow trout (Velíšek and Svobodová, 2004; Velíšek et al. 2007), thus this anaesthetic may be assumed as safe of for grayling. Evidently, intramuscular injection had no effect on the post-stripping mortality of the females used. The mortality of stripped females is primarily caused by manipulation during the stripping season.

In conclusion, our experiment suggested that administration of hormonal preparations (Gonazon and Supergestran) is not essential for artificial spawning in the hatchery-reared grayling females under optimal temperature conditions. On the other hand, post-stripping mortality is unaffected by intramuscular injection. With regard to earlier published results of some authors, treatment by of the GnRH agonist can thus be used as prevention against negative natural influences in hatcheries. The effect of different preparations on egg viability is suitable for detailed research.

\section{Acknowledgments}

This study was supported by the Ministry of Agriculture of the Czech Republic, the CENAKVA CZ.1.05/2.1.00/01.0024 project, the project LO1205 with a financial support from the MEYS of the CR under the NPU I program and the Grant Agency of USB GAJU 087/2013/Z.

\section{References}

Burgus R, Butcher M, Ling N, Monahan M, Rivier J, Fellows R, Amoss M, Blackwel R, Vale W, Guillemi R 1971: Molecular structure of hypothalamic factor of ovine origin controlling secretion of hypophyseal gonadotropic luteinizing hormone (LH). CR ACAD SCI D NAT 273: 1611-1613 
Harsányi A, Aschenbrenner P 2002: Development of the stock and reproduction of grayling (Thymallus thymallus) in lower Bavaria (in Czech). Bulletin VURH Vodňany 38: 99-127

Kouřil J, Barth T, Fila F, Přihoda J, Flegel M 1987a: The use of synthetic salmon GnRH analogue in induction of ovulation in female grayling (Thymallus thymallus L.) (in Czech). Bulletin VÚRH Vodňany 23: 3-10

Kouřil J, Barth T, Štěpan J, Přihoda J, Flegel M 1987b: Stripping of female grayling (Thymallus thymallus L.): ovulation induced with LH-RH analog and carp pituitary (in Czech). Bulletin VÚRH Vodňany 23: 3-11

Leszek A, Kowalewski M, Ciesla M 2000: Artificial propagation of grayling in Poland (in Czech). Bulletin VÚRH Vodňany 36: 126-129

Luczynski M, Zaporowski R, Golonka J 1986: Rearing of European grayling (Thymallus thymallus), larvae using dry and live ford. Aquac Fish Manage 17: 275-280

Mikolajczyk T, Sokolowska-Mikolajczyk M, Szczerbik P, Duc M, Goryczko K, Dobosz S, Glogowski J, Epler P, Enright WJ 2008: The effects of the GnRH agonist, azagly-nafarelin (Gonazon ${ }^{\mathrm{TM}}$ ), on ovulation and egg viability in the European grayling (Thymallus thymallus L.). Aquaculture 281: 126-130

Mylonas CC, Fostier A, Zanuy S 2010: Broodstock management and hormonal manipulations of fish reproduction. Gen Comp Endocr 165: 516-534

Pavlík L 2000: The history and own experience with grayling culture under the conditions of fisheries practice (in Czech). Bulletin VÚRH Vodňany 36: 107-109

Randák T 2002: The effect of selected ovulation-inducing preparations on the course of reproduction of grayling (Thymallus thymallus L.) and on their mortality during the post-reproductive period (in Czech). Bulletin VÚRH Vodňany 38: 168-174

Randak T, Pokorny J, Sedlecky V, Sucharda M 2000: Ovulation synchronization in grayling (Thymallus thymallus) at Husinec local organization of the Czech anglers union (in Czech). Bulletin VÚRH Vodňany 36: 119-125

Uiblein F, Jagsch A, Honsig-Erlenburg W, Weiss S 2001: Status, habitat use, and vulnerability of the European grayling in Austrian waters. J Fish Biol 59: 223-247

Velíšek J, Svobodová Z 2002: Anaesthesia of rainbow trout (Oncorhynchus mykiss) with 2-phenoxyethanol: Acute toxicity and biochemical blood profile. Acta Vet Brno 73: 379- 384

Velíšek J, Svobodová Z, Piačková V 2007: Effects of 2-Phenoxyethanol anaesthesia on haematological profile on common carp (Cyprinus carpio) and rainbow trout (Oncorhynchus mykiss). Acta Vet Brno 76: 487-492 